\title{
Effect of Oxidation-Reduction Fluctuations on Metal Mobility of Speciated Metals and Arsenic in Bottom Sediments of Middleton River, Bayelsa State, Nigeria
}

\author{
*AIGBERUA, AO; TARAWOU, JT; ABASI, CY
}

\author{
Department of Chemical Sciences, Faculty of Science, Niger Delta University, Wilberforce Island, Bayelsa State, Nigeria. \\ *Corresponding Author Email:ozedee101@gmail.com
}

\begin{abstract}
Speciation and chemical mobility of heavy metals were assessed with a view to provide information on bioavailability of metals in a sediment matrix in order to account for the vulnerability of sediment dwelling fauna within the Middleton river ecosystem. Sediment was collected in triplicate from seven locations (five reflecting activities of oil installations in the study area and two controls). Sediments were collected in the months of March and August 2017 to reflect the dry and wet seasons respectively. Concentration of metals in each fraction was determined using a GBC Avanta Atomic Absorption Spectrophotometer. The residual fraction was the most important for $\mathrm{Cr}$ with average levels of (49.4\%) and $(41.1 \%)$ for the dry and wet seasons respectively. Also, the most prevalent fractions of $\mathrm{Zn}$ were the residual fractions which revealed $(31.7 \%)$ and $(42.6 \%)$ during the dry and wet seasons respectively. The metalloid (As) had (14.7\%) and $(13.8 \%)$ of its total concentration bound to the residual and crystalline Fe-oxide fractions during the dry and wet seasons respectively. The oxidation-reduction potential (ORP) was measured electrometrically using a redox potential meter; ORP ranged from $(+288.67$ to $+351.33 \mathrm{mV})$ and $(+331.00$ to $+465.67 \mathrm{mV})$ for the dry and wet seasons respectively, hence, depicting a fairly oxidizing sediment environment. Mobility factor of metals depicted ( $\mathrm{As}>\mathrm{Cu}>\mathrm{Cr}$ ) and ( $\mathrm{As}>\mathrm{Cr}>\mathrm{Cu}$ ) for the dry and wet seasons respectively. The effect of oxidation-reduction potential on metal mobility revealed the transportability of chromium with increasing redox potential while arsenic was barely mobile with increasing oxidation level. Also, zinc mobility diminished strongly with increasing oxidation-reduction potential.
\end{abstract}

\section{DOI: https://dx.doi.org/10.4314/jasem.v22i9.25}

Copyright: Copyright $@ 2018$ Aigberua et al. This is an open access article distributed under the Creative Commons Attribution License (CCL), which permits unrestricted use, distribution, and reproduction in any medium, provided the original work is properly cited.

Dates: Received: 28 August 2018; Revised: 10 September 2018; Accepted: 30 September 2018

Keywords: Speciation, chemical mobility, bioavailability, Middleton River

Heavy metals can be seen as essential (macro and micro) and non-essential (toxic) elements. Some essential elements include $\mathrm{Cr}, \mathrm{Co}, \mathrm{Cu}, \mathrm{Fe}, \mathrm{Mn}, \mathrm{Ni}, \mathrm{Zn}$, while some non-essential elements include $\mathrm{Pb}$, As and $\mathrm{Cd}$. The essential elements contribute significantly to the nutrient requirements of the human organism but possess the potential to be toxic in case of excessive intake. Chemical speciation is the process of identifying and quantifying different species, forms of phases of elements that are present in a material (environmental sample) (Ure et al., 1993). The sediments existing at the bottom of the water column play a major role in the pollution scheme of the river systems by heavy metals. Environmental conditions such as $\mathrm{pH}$, redox potential or the presence of organic chelators can lead to the release of heavy metals into a water column (Forstner, 1985). Heavy metals in sediment usually remain inert and may be released back into the water column if there are disturbances (Olivares-Rieumont et al., 2005).

The Niger Delta region of Nigeria remains the major fulcrum of crude oil production as much as Nigeria's industrial development is linked to its petroleum stock.
Government resolutions are made and budgets proposed based on projected crude oil exports. Crude oil production in Nigeria often rises and falls as a result of activities of militia, sabotage, illegal bunkering and pipeline vandalism. During these activities, oil spills into nearby environment (that is, soil, water and sediment). Oil spill incidence is caused by several factors including vandalism and rupture of pipeline (Aigberua et al., 2017). About $95 \%$ of the population of the Okrika people who live along the Okrika River and its estuaries solely depend on groundwater for their domestic uses since their surface water sources are severely polluted by the direct discharge of domestic and industrial effluents and wastes into them (Tamunobereton-ari et al., 2011). Therefore, the presence and concentration of heavy metals in water bodies may be influenced by human activities even as sediments serve as the final sink of heavy metals in the water body (Asimiea and Lawal, 2017). Their mobility in sediment and soil are assessed by sequential extraction procedures (Iwegbue et al., 2007).

Reduction-oxidation reaction reflects the processes involved in the flow of electrons from reducing agents 
(reducer) to an oxidizing agent (oxidant). Oxidized soils have values ranging from +400 to $+700 \mathrm{mV}$ while reduced soils may have values from -250 to $-300 \mathrm{mV}$ (Sparks, 1995). The redox status of a soil is an important factor in considering metal speciation in soils for both direct and indirect reasons. Metals that are directly sensitive to redox changes in soils include: $\mathrm{As}, \mathrm{Cr}, \mathrm{Hg}$ and $\mathrm{Se}$. They all have reduced and oxidized forms and in many cases the redox status influences their toxicity and mobility. For example, reduced $\mathrm{Cr}$ (III) has a low hazard associated with it while oxidized $\mathrm{Cr}$ (VI) can be quite toxic to organisms (Fendorf and Sparks, 1994). The solubility of $\mathrm{Pb}, \mathrm{Cd}$ and $\mathrm{Zn}$ has been reported to have increased with decreasing redox potential under the same $\mathrm{pH}$ values (Chuan et al., 1996). However, Bjerre and Schierup (1985) found conflicting reports regarding the effect of redox conditions on metal solubility: some studies reported that $\mathrm{Zn}$ availability increases in poorly drained water logged soils whilst others arrive at the opposite conclusion. In addition, it was not specified if the opposing trend was due to varying circumstances such as different environmental conditions or soil types. The nine-stage multi-step extraction procedure has been used to understand the concept of bioavailability, mobility and lability of elements in the environment (Olutona et al., 2012). The fate and chemical behaviour of metals and their bioavailability in the environment results in the identification and quantification of different forms or species of the elements. The nine-stage multi-step extraction scheme was adopted in the study of bottom sediments collected from the Middleton River. The present study was driven by the need to investigate the role that oxidation-reduction fluctuations play in the available metal species that are found in bottom sediments of the Middleton River across the dry and rainy seasons.

\section{MATERIALS AND METHODS}

Study area: The Middleton River is a creek located in the Southern Ijaw local government area of Bayelsa state, the river is also referred to as Middleton creek. Its geographical coordinates lie within the latitude $4^{\circ}$ 30 ' 30.49" $\mathrm{N}$ and longitude $5^{\circ} 43$ ' 39.94" $\mathrm{E}$ and is bound majorly by the neighbouring Azuzuama host community. The Middleton River is home to numerous oil and gas installations (oil wells, pipelines and manifolds) which serve as supply lines to neighbouring oil flow stations within the region. Some oil pipelines within the area are illegally tapped for the diversion of crude oil by bunkers while pipeline vandalism is not uncommon. The tidal nature of the river allows for the run-off of spilt crude into surrounding freshwater; this spilt crude sometimes emanate from the activities of bunkers within the environment, hence, it is not unusual to observe oil sheen on the water surface. As is typical of most communities living along the river shorelines in the Niger Delta region, other forms of indiscriminate and uncontrolled municipal discharges negatively impact on the overall quality of the aquatic environment (Aigberua et al., 2017). The predominant occupation of the inhabitants of Azuzuama community is majorly fishing and farming, the study area and sample locations are as shown in Figure 1.

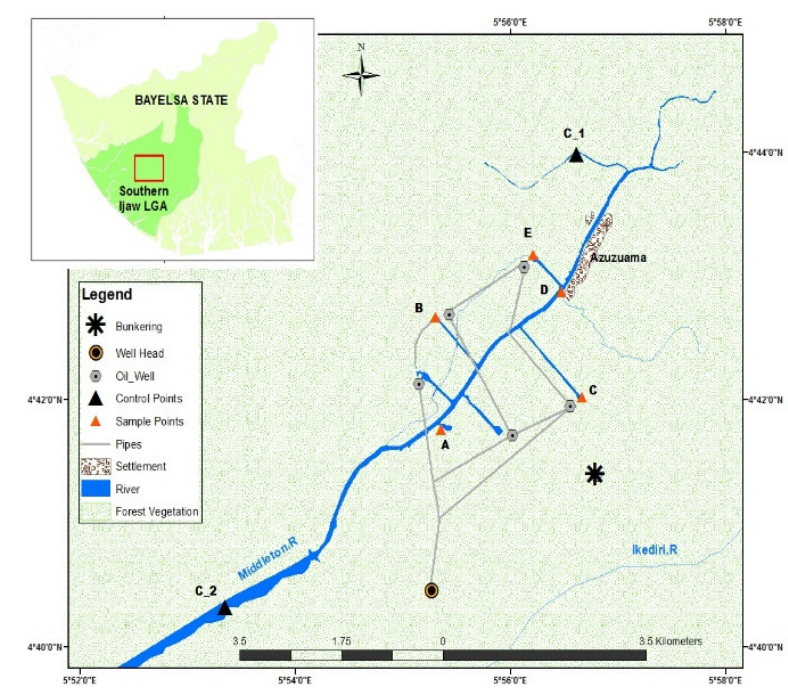

Fig. 1: Location Map of sediment sampling points on the Middleton River

Field Sampling: Sediment samples were collected in a manner that reflected the oil and gas activities within the river. Five (5) sampling points were established from potential point sources of oil pollution while two (2) control points were sampled at about $1 \mathrm{~km}$ upstream (C1) and $2 \mathrm{~km}$ downstream (C2) distances from pollution point sources (Figure 1). An Eckmann grab was deployed to collect bottom sediments and each sampling point was geo-referenced with a handheld Garmin Etrex model GPS; the coordinates were recorded as: A (N04 41'48.1', E005' 55' 20.0”), B (N04'42' 40.2", E005' 55' 18.4"), C (N04 42' 00.3", E005 56' 38.0'), D (N04 42' 51.3”, E005' 56' 27.9”), E (N04' 43' 09.0”, E005' 56' 11.2”), Control 1 (N04 $\left.{ }^{\circ} 43^{\prime} 58.3^{\prime \prime},{\mathrm{E} 005^{\circ}}^{\circ} 56^{\prime} 41.5^{\prime \prime}\right)$ and Control 2 (N04 ${ }^{\circ}$ 40'.068”, E005 53'.018'). Triplicate samples were collected for each sampling point and transferred into pre-cleaned polyethylene bags before been stored in an ice chest.

Sample Preparation, Analytical Validation and Quality Control Procedure: Sediment samples were air-dried at room temperature, homogenized by grinding and sieved through a $2 \mathrm{~mm}$ mesh size sieve before being further sub sampled and labelled in 
plastic vials. Glassware was properly cleaned, ovendried and cooled in a desiccator. Reagent blank was prepared for each fraction of the sequential extraction. A series of working standard solutions of $0.5,1,2,5$, 10 and $100 \mathrm{mg} / \mathrm{l}$ were prepared from the stock standard solution of each test metal; this was done by diluting known volumes of the stock solution in $100 \mathrm{ml}$ volumetric flasks using distilled water. $1000 \mathrm{mg} / \mathrm{l}$ of an AccuStandard (USA) metal stock solution of each metal was diluted accordingly to prepare a series of intermediate standard solutions which were used for the calibration of the Flame Atomic Absorption Spectrophotometer (FAAS). During analysis, method blanks and standard solutions were aspirated at the start, midpoint and end of each metal run. The following working wavelengths were used: $\mathrm{Cr}$ (357.9 nm), Zn (213.9 nm), As (193.7 nm). Also, redox potential was read electrometrically using a RoHS ORP-619 meter dipped in a 1:1 sediment solution of $20 \mathrm{~g}$ air-dried sediment and $20 \mathrm{ml}$ distilled water.

Reagents and Chemicals: The reagents and chemicals used were of analytical grade, some of which included: ammonium nitrate (Analytical Reagent, Yueqiao chemicals, China), ammonium nitrate (Analytical Reagent, Yueqiao chemicals, China), 96\% glacial acetic acid (Riedel-De Haen, Germany), hydroxylamine hydrochloride (Analytical Reagent, Guangdong Guanghua Sci-Tech Co., Ltd Shantou, China), EDTA Disodium salt (Analytical Reagent, Interchem Europe (UK) Ltd), ammonium oxalate (LabTech Chemicals, India), ascorbic acid (BDH Chemicals Ltd, Poole England), hydrofluoric acid (BDH Chemicals Ltd, Poole England), Hydrofluoric acid (BDH Chemicals Ltd, Poole England), 65\% nitric acid (Riedel-De Haen, Germany), 37\% hydrochloric acid (Sigma-Aldrich Chemicals, USA), sodium hexametaphosphate (Analytical Reagents Cartivalues Scientific Enterprises, (Singapore) PTE. Ltd), potassium dichromate (Analytical Reagent, Kermel - Colmar, France), sulphuric acid (BDH Chemicals Ltd, Poole England), 1,10-phenanthroline hydrate (Hopkins \& Williams, Chadwell Health Essex, UK) and ferrous sulphate (Analytical Reagent, Kermel - Colmar, France). All standard solutions were prepared using distilled water; working standards of the ten (10) metals to be determined were prepared by diluting different known volumes of their stock solutions $(1,000 \mathrm{mg} / \mathrm{l})$.

Sequential Extraction of Heavy Metals: The ninestage sequential extraction scheme for metal fractionation reported by (Miller et al., 1986; Zeien and Bruemmer, 1989; Olutona et al., 2012) was used. The analytical speciation scheme used in this study is a slightly modified version of selective sequential extraction procedure by Tessier et al., (1979). Except for the introduction of two important factors; water soluble and plant available (Olutona et al., 2012).

One gram of each sediment sample was weighed and subjected to a nine-stage sequential extraction process using different extracting solutions as applicable for each extraction step. Distilled water was used to wash the residues following subsequent extractions in order to ensure selective dissolution and to avoid possible inter-phase mixing or cross-contamination between the extraction fluids. All samples were run in triplicate; the detailed analytical protocol adopted is as follows:

Fraction 1: Water soluble metals: Water soluble metals were extracted with a solution of $50 \mathrm{ml}$ distilled water at $\mathrm{pH} 7.0$ and at $28^{\circ} \mathrm{C}$ for $2 \mathrm{~h}$.

Fraction 2: Exchangeable metals: The residue from (water soluble metals) was extracted with $25 \mathrm{ml}$ of 1.0 $\mathrm{M} \mathrm{NH} \mathrm{COOCH}_{3}(\mathrm{pH}=7.0)$. The suspension was agitated for $30 \mathrm{~min}$ at $28^{\circ} \mathrm{C}$.

Fraction 3: Metals bound to carbonate: The residue from (exchangeable metals) was extracted with $3 \mathrm{M}$ sodium acetate solution $\left(\mathrm{CH}_{3} \mathrm{COONa}\right)$ adjusted to $\mathrm{pH}$ 5.0 with acetic acid $\left(\mathrm{CH}_{3} \mathrm{COOH}\right)$. The suspension was agitated for $5 \mathrm{~h}$.

Fraction 4: Plant available metals: The residue from (metals bound to carbonate) was extracted by shaking with a solution mixture consisting $50 \mathrm{ml}$ of $0.025 \mathrm{M}$ $\mathrm{HCI}+0.05 \mathrm{M} \mathrm{H}_{2} \mathrm{SO}_{4}$ for $30 \mathrm{~min}$ at $28^{\circ} \mathrm{C}$.

Fraction 5: Metals bound to Mn-oxide: The residue from (plant available metals) was shaken for $30 \mathrm{~min}$ at $28^{\circ} \mathrm{C}$ with a solution of $25 \mathrm{ml} 0.1 \mathrm{M}$ hydroxylamine hydrochloride $\left(\mathrm{NH}_{2} \mathrm{OH} . \mathrm{HCl}\right)$ in $25 \%$ acetic acid $\left(\mathrm{CH}_{3} \mathrm{COOH}\right)$ (pH 2 to 3$)$.

Fraction 6: Metals bound to amorphous Fe-oxide: The residue from (Mn-oxide bound metals) was extracted with $25 \mathrm{ml}$ of $0.2 \mathrm{M}$ Ammonium oxalate $\left[\left(\mathrm{NH}_{4}\right)_{2} \mathrm{C}_{2} \mathrm{O}_{4}\right]$ (pH 3.0) for $30 \mathrm{~min}$ at $50^{\circ} \mathrm{C}$ using a water bath with occasional stirring.

Fraction 7: Metals bound to crystalline Fe-oxide: The residue from (amorphous Fe-oxide bound metals) was extracted using a mixture of $0.2 \mathrm{M}$ Ammonium oxalate $\left[\left(\mathrm{NH}_{4}\right)_{2} \mathrm{C}_{2} \mathrm{O}_{4}\right]$ and $0.1 \mathrm{M}$ ascorbic acid $(\mathrm{pH} 3.25)$ and it was heated in a water bath with occasional stirring at $100^{\circ} \mathrm{C}$ for $30 \mathrm{~min}$.

Fraction 8: Metals bound to organic matter: The residue from (crystalline Fe-oxide bound metals) was 
extracted with $10 \mathrm{ml}$ of $0.02 \mathrm{M} \mathrm{HNO}_{3}$ and $15 \mathrm{ml}$ of $30 \% \mathrm{H}_{2} \mathrm{O}_{2}$ (adjusted to $\mathrm{pH} 2$ with $\mathrm{HNO}_{3}$ ). The mixture was then heated to $85^{\circ} \mathrm{C}$ for $5 \mathrm{~h}$ with occasional agitation. A second $15 \mathrm{ml}$ of $30 \% \mathrm{H}_{2} \mathrm{O}_{2}$ (pH 2 with $\mathrm{HNO}_{3}$ ) was added and the mixture was heated again to $85^{\circ} \mathrm{C}$ for $3 \mathrm{~h}$ with intermittent agitation. After cooling, $5 \mathrm{ml}$ of $3.2 \mathrm{M} \mathrm{NH}_{4} \mathrm{COOCH}_{3}$ in $20 \%$ (v/v) $\mathrm{HNO}_{3}$ was added and the samples diluted to $20 \mathrm{ml}$ and agitated continuously for $30 \mathrm{~min}$.

Fraction 9: Residual metals: The residue from (organic matter bound metals) was digested with a mixture of concentrated $\mathrm{HF}, \mathrm{HNO}_{3}$ and $\mathrm{HCIO}_{4}$ for $8 \mathrm{~h}$. Mobility Factors of heavy metals in bottom sediments of the Middleton River: The operationally defined extraction sequence fractionates the heavy metals in the sediment in order of decreasing solubility. For a nine stage sequential extraction procedure, the water soluble, exchangeable and carbonate $(\mathrm{F} 1+\mathrm{F} 2+\mathrm{F} 3)$ fractions which are the early fractions reflect the most reactive and presumably the most mobile and potentially bioavailable fractions (Kersten and Forstner, 1989; Fedotov and Miro, 2008) (Table 1).
The relative index of heavy metal mobility was calculated as a mobility factor (MF) (Kabala and Singh, 2001) on the basis of the equation 1 .

$$
M F=\left[\frac{(F 1+F 2+F 3)}{(F 1+F 2+F 3+F 4+F 5+F 6+F 7+F 8+F 9)}\right] \times 100
$$

A high mobility factor (MF) value for heavy metals in soil has been interpreted as evidence of relatively high lability and biological availability (Kabala and Singh, 2001). Heavy metal mobility factor increased with increasing solubility and mobility within the Middleton River sediment system. A percentage ratio of the sum of experimental data generated from metal analysis of fractions 1 to 3 (the readily mobile fractions) were evaluated against those obtained from the summation of all fractions (from 1 to 9; the mobile and immobile fractions). The resulting mobility factors reflected potential bioavailability and toxicity of each metal.

Table 1: Operationally defined fraction and extracted components (Fedotov and Miro, 2008)

\begin{tabular}{|c|c|c|c|}
\hline Defined Fraction & Extracted Components & $\begin{array}{l}\text { Physicochemical } \\
\text { mobility }\end{array}$ & $\begin{array}{l}\text { Potential } \\
\text { bioavailability }\end{array}$ \\
\hline Water soluble & Free ions & Mobile & Easily available \\
\hline Exchangeable & $\begin{array}{l}\text { Exchangeable ions (metals retained by weak } \\
\text { electrostatic interactions) }\end{array}$ & Mobile & Easily available \\
\hline Acid soluble & Carbonates (for non-calcareous soils) & Easily mobilizable & Easily available \\
\hline Easily reducible & Mn oxyhydroxides & Readily mobilizable & Readily available \\
\hline Easily oxidizable & Metal-organic complexes & Readily mobilizable & Readily available \\
\hline Moderately reducible & Amorphous $\mathrm{Fe}$ (and $\mathrm{Al}$ ) oxyhydroxides & Poorly mobilizable & Poorly available \\
\hline Moderately and poorly oxidizable & Refractory organic compounds and sulfides & Poorly mobilizable & Poorly available \\
\hline Poorly reducible & Crystalline $\mathrm{Fe}$ and $\mathrm{Al}$ oxyhydroxides & Poorly mobilizable & Poorly available \\
\hline Residual & $\begin{array}{l}\text { Mineral lattice (metals retained within the } \\
\text { crystal structure) }\end{array}$ & Immobile & Unavailable \\
\hline
\end{tabular}

Where, $F 1=$ Water soluble fraction; $F 2=$ Exchangeable fraction; $F 3=$ Carbonate fraction; $F 4=$ Plant available fraction; F5 = Mn-oxide fraction; F6 = Amorphous Fe-oxide fraction; F7 = Crystalline Fe-oxide fraction; F8 = Organic matter bound fraction; F9 = Residual fraction

Table 2: Percentage speciation of metals in different sediment fractions

\begin{tabular}{lcccccc}
\hline Heavy Metal Fractions & \multicolumn{3}{c}{ Dry Season } & \multicolumn{3}{c}{ Wet Season } \\
\cline { 2 - 7 } & $\begin{array}{c}\% \\
\text { speciation } \\
(\mathrm{Cr})\end{array}$ & $\begin{array}{c}\% \\
\text { speciation } \\
(\mathrm{Zn})\end{array}$ & $\begin{array}{c}\% \\
\text { speciation } \\
(\mathrm{As})\end{array}$ & $\begin{array}{c}\% \\
\text { speciation } \\
(\mathrm{Cr})\end{array}$ & $\begin{array}{c}\% \\
\text { speciation } \\
(\mathrm{Zn})\end{array}$ & $\begin{array}{c}\% \\
\text { speciation } \\
(\mathrm{As})\end{array}$ \\
\hline Water-soluble (F1) & 5.6 & 27.2 & 5.7 & 21.1 & 8.3 & 9.6 \\
Exchangeable (F2) & 1.5 & 14.0 & 13.4 & 0.7 & 8.6 & 10.2 \\
Carbonate-bound (F3) & 2.8 & 3.1 & 11.8 & 3.0 & 2.1 & 11.4 \\
Plant available (F4) & 3.2 & 0.7 & 10.3 & 1.8 & 0.2 & 9.9 \\
Mn-oxide (F5) & 3.0 & 1.4 & 11.7 & 1.2 & 2.3 & 11.6 \\
Amorphous Fe-oxide (F6) & 8.2 & 4.5 & 9.8 & 7.2 & 8.4 & 11.9 \\
Crystalline Fe-oxide (F7) & 7.1 & 4.4 & 11.0 & 7.1 & 16.6 & 13.8 \\
Organic bound (F8) & 19.3 & 13.0 & 11.7 & 16.8 & 10.7 & 10.1 \\
Residual (F9) & 49.4 & 31.7 & 14.7 & 41.1 & 42.6 & 11.5 \\
\hline
\end{tabular}

\section{RESULTS AND DISCUSSION}

Heavy metal speciation of bottom sediment: The obtained data shows the heavy metal species or ions that characterize the bottom sediments of the Middleton River in Southern Ijaw LGA, Bayelsa State.
The essential and non-essential metal species studied includes: $\mathrm{Cr}, \mathrm{Zn}$ and As. The identified metal species represents the inert and mobile metal fractions which can either become immobile or bioavailable within the aquatic ecosystem, depending on the prevailing metal 
fractions that are found in the underlying sediment strata. Metal fractions were quantified across different sampling locations (impacted and control sites) along the same river. The effect of seasonal (dry and wet) variation was also assessed. This data was generated from biannual sampling across the two months of March and August 2017 to reflect the dry and wet seasons respectively. A total of forty-two sediment samples were analysed for three (3) metal fractions or species by applying multi-step extraction procedures as similarly used by Miller et al., (1986) and Olutona et al., (2012). The result was presented in Table 2 as percentage metal species or fractions (F1 to F9) in sediment.

Heavy Metals Fractionation Patterns: Chromium: During the dry season, the levels of chromium in the sediment showed that the residual fraction $(49.4 \%)$ and organic matter bound fraction (19.3\%) were mostly predominant. On the other hand, wet season chromium levels were found in residual fraction $(41.1 \%)$ and water soluble $(21.1 \%)$, followed by organic matter bound fraction $(16.8 \%)$, therefore, the residual fractions represent the most associated species for chromium (Table 1). This was similar to the findings of Iwegbue et al., (2007) where chromium in Ase River was reported to be associated with organic, residual and $\mathrm{Fe}-\mathrm{Mn}$ oxide fraction. This finding contradicted the earlier report of Ideriah et al., (2013) that chromium in soils around Abara and Ozuzu oil wells were found to be highest in the exchangeable fraction and lowest in the residual fraction during the dry season. Chromium levels in surface waters of the Middleton River may have resulted from industrial waste waters and indiscriminate discharge of municipal sewage and the fact that chromium readily forms ionic species (Morel and Hering, 1994).

Zinc: During the dry season, the distribution of zinc in sediment revealed that residual $(31.7 \%)$ and water soluble $(27.2 \%)$ were the most predominant fractions. This may have been partly responsible for the bioavailable concentrations of zinc in surface waters of the Middleton River (Aigberua et al., 2017). On the other hand, the wet season depicted mostly the immobile fractions as the residual (42.6\%) and crystalline Fe-oxide (16.6\%) were mostly predominant (Table 1). Similarly, Olutona et al., (2012) had reported zinc to be associated with the exchangeable and carbonate fractions. Osakwe et al., (2014) had reported zinc to be in the carbonate, organic and residual fractions. Iwegbue et al., (2007) had reported zinc to be associated with the residual, $\mathrm{Fe}-\mathrm{Mn}$ oxide and carbonate fractions. Leizou et al., (2015) had reported sediments of the Pennington River in Bayelsa state to have zinc in the residual fraction. The findings of this study did not agree with that of Ideriah et al., (2013) where zinc was observed to have its highest concentration in the exchangeable fraction and lowest concentration in the residual fraction within the dry season.

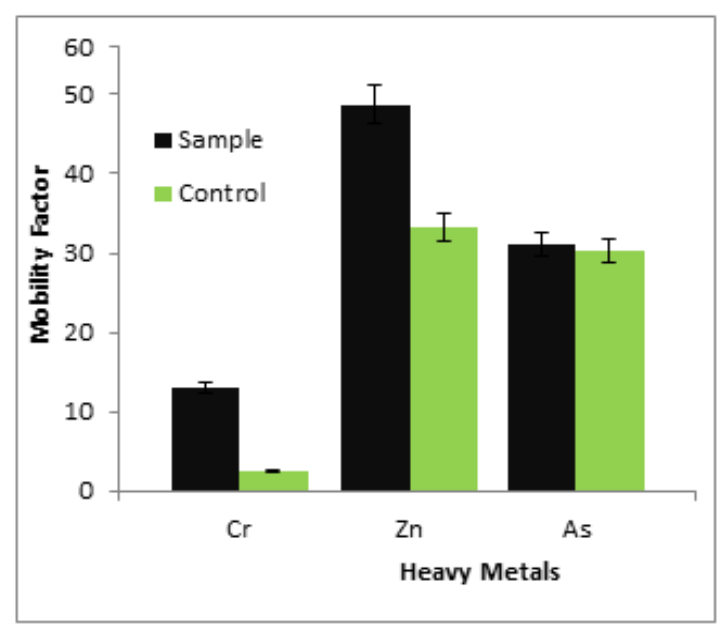

Fig. 2: Heavy metal mobility factors during the dry season

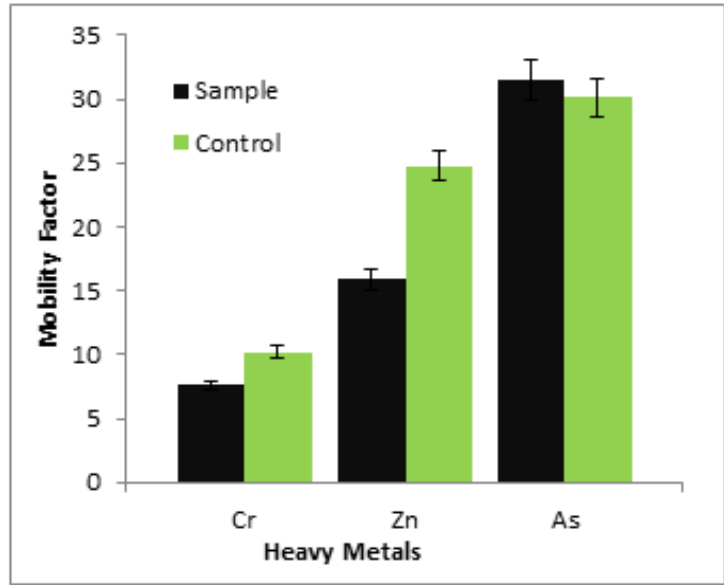

Fig. 3: Heavy metal mobility factors during the wet season

Arsenic: The distribution of arsenic in sediment of the Middleton river showed highest percentage in residual fraction (14.7\%) and exchangeable fraction (13.4\%), followed by carbonate bound fraction (11.8\%). However, the predominant fractions were found in the residual phases during the wet season as crystalline Fe-oxide fraction (13.8\%) and amorphous Fe-oxide fraction $(11.9 \%)$, being closely followed by the Mnoxide fraction $(11.6 \%)$ (Table 1). The findings were in partial agreement with Leizou et al., (2015) where arsenic was observed to be solely dominant in the exchangeable fractions of the Pennington river sediments in Bayelsa state. Hence, arsenic was distributed in potentially bioavailable species within the underlying sediments of the Middleton River. 
The mobility factors (MF) of the metals for all the sediment sampling points across the Middleton River were presented in Figures 2 and 3 for the dry and wet seasons respectively. The observed trend for the mobility factors of metals depicted $\mathrm{Zn}>\mathrm{As}>\mathrm{Cr}$ and As $>\mathrm{Zn}>\mathrm{Cr}$ for dry and wet seasons respectively across both sample and control locations. The dry and wet seasons depicted the period of most mobility for $\mathrm{Zn}$ and As across both the sample and control locations respectively. Consequently, chromium depicted the least mobility factor and bioavailability across both seasons and sample locations. This finding partly agreed with that of Osakwe et al., (2014) where $\mathrm{Zn}$ was reported to depict high mobility factor indices as shown in the trends $(\mathrm{Ni}>\mathrm{Zn}>\mathrm{Cd}>\mathrm{Cu}>\mathrm{Pb}>\mathrm{Fe})$ and $(\mathrm{Cd}>\mathrm{Ni}>\mathrm{Zn}>\mathrm{Pb}>\mathrm{Cu}>\mathrm{Fe})$ for bottom sediments of the Imo River system during the dry and wet seasons respectively. Arsenic depicted lower mobility factor during the dry season when compared to $\mathrm{Zn}$ (Figures 2 and 3). This may have been due to its sensitivity to mobilization under both oxidizing and reducing conditions (Smedley, 2002).

Similarly, the poor mobility of chromium may have stemmed from the fact that chromium forms chelates with humic and fulvic acids (Morel and Hering, 1994). The concentration of iron in the bottom sediments suggests the presence of humic acids. This may have been responsible for the seemingly low mobility factor of chromium in the sample and control points across both seasons as reported in this study.

Effect of oxidation-reduction fluxes on mobility factor of heavy metals in sediments: The effect of redox changes on the toxicity and mobility of speciated metals and metalloid in underlying sediments of the Middleton River is depicted in (Figure 4).

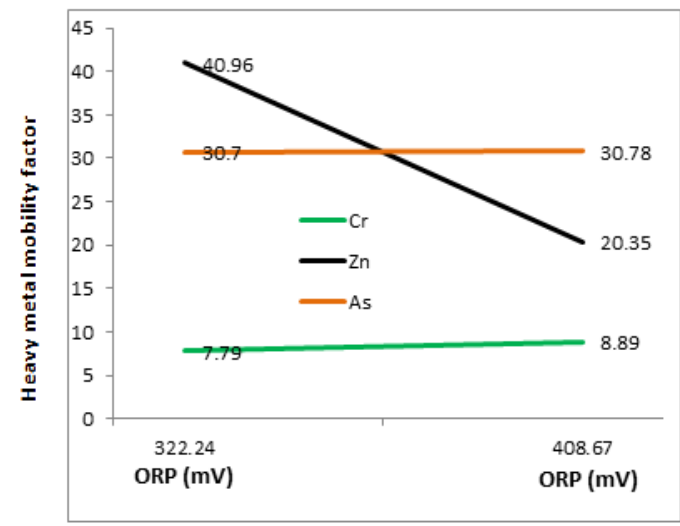

Fig. 4: Heavy metal mobility factor versus ORP levels in sediment

Chromium was readily mobile as oxidation-reduction potential increased. This was in agreement with
Fendorf and Sparks (1994) where they had reported $\mathrm{As}, \mathrm{Cr}, \mathrm{Hg}$ and Se to be directly sensitive to redox changes in soils. However, the slight increase in mobility factor of arsenic depicted a slower response of the metalloid to an increased oxidation-reduction level. Also, zinc mobility in sediment decreased sharply with increasing oxidation-reduction potential. The findings from this study was in agreement with Chuan et al., (1996) where the solubility of $\mathrm{Pb}, \mathrm{Cd}$ and $\mathrm{Zn}$ was reported to have increased with decreasing redox potential under the same $\mathrm{pH}$ values.

Conclusion: The sediment matrix was a fairly oxidizing environment during both seasons. Chromium was transportable as redox potential increased while the insignificant gain in mobility factor of arsenic with respect to redox potential delineated a sedate response of the metalloid with increased oxidation level. In addition, zinc mobility in sediment diminished strongly with increasing redox potential. The oxidation level of the sediment environment suggests that the sparingly soluble oxides and hydroxide forms of chromium, zinc and arsenic are formed.

\section{REFERENCES}

Aigberua, AO; Tarawou, JT; Abasi, CY (2017). Spatial and Seasonal Assessment of Heavy Metals in Surface Waters of the Middleton River in the Niger Delta, Nigeria. International Journal of Natural Resource Ecology and Management. 2(5): 94-98.

Asimiea, AO; Lawal, O (2017). Investigation of relationship between sediment characteristics and heavy metals across seasons in the Lower Forcados River, Nigeria. J. Appl. Sci. Environ. Manage. 21(1): 208-215.

Bjerre, GK; Schierup, HH (1985). Influence of waterlogging on availability and uptake of heavy metals by oat grown in different soils. Plant and Soil. 88(1): 45-56.

Chuan, MC; Shu, GY; Liu, JC (1996). Solubility of Heavy Metals in a Contaminated Soil: Effects of Redox Potential and $\mathrm{pH}$. Water, Air and Soil Pollution. 90: 543-556.

Fedotov, PS; Miro, M (2008). Fractionation and mobility of trace elements in soils and sediments. In: Violante, A; Huang, PM; Gadd, GM (eds). Biophysico-Chemical Processes of Heavy Metals and Metalloids in Soil Environments. Wiley-Jupac Series Vol 1, John Wiley \& Sons, Hoboken, NY. pp: 467-520. 
Fendorf, SE; Sparks, DL (1994). Mechanisms of chromium (III) sorption on silica. Effect of reaction conditions. Environmental Science and Technology. 28: 290.

Forstner, U (1985). Chemical forms and reactivities of metals in sediment. In R. Leschber et al. (ed) Chemical Methods of Assessing Bioavailable Metal in Sludges and Soils. Elsevier, London. pp. 1-30.

Ideriah, TJK; Ikpe, FN; Nwanjoku, FN (2013). Distribution and Speciation of Heavy Metals in Crude Oil Contaminated Soils from Niger Delta, Nigeria. World Environment. 3(1): 18-28.

Iwegbue, CMA; Eghwrudje, MO; Nwajei, GE; Egboh, SHO (2007). Chemical Speciation ofheavy metals in the Ase River sediment, Niger Delta, Nigeria. Chemical Speciation \& Bioavailability. 19(3): 117127.

Kabala, C; Singh, BR (2001). Fractionation and Mobility of copper, lead and zinc in vicinity of copper smelter. J. Env. Qual. 30: 485-492.

Kersten, M; Forstner, U (1989). Speciation of trace elements in sediments. In: Batley, G (ed). Trace Element Speciation. Analytical Methods and Problems. CRC Press, Boca Raton, FL. 245.

Leizou, KE; Horsfall, M; Spiff, AI (2015). Speciation of Some Heavy Metals in Sediments of the Pennington River, Bayelsa State, Nigeria. American Chemical Science Journal. 5(3): 238246.

Miller, W; Martens, D; Zelazny, L; Kornegay, E (1986). Forms of solid phase copper in copperenriched swine manure. J. Env. Qual. 15:69-72.

Morel, FMM; Hering, JG (1994). Principles and applications of aquatic chemistry. John Wiley Sons Inc, New York.

Olivares-Rieumont, S; de la Rosa, D; Lima, L; Graham, DW; D'Allesandro, K; Borroto, J; Sanchez, J (2005). Assessment of heavy metal levels in Almendares River Sediments-Havana City, Cuba. Water Res. 39(16): 3945-3953.
Olutona, GE; Aribisala, OG; Akintunde, EA (2012). A study of chemical speciation of metals in aquatic bottom sediment of Aiba reservoir, Iwo, Nigeria. Afr. J. Environ. Sci. Technol. 6(8): 312-321.

Osakwe, JO; Adowei, P; Horsfall, MJ (2014). Evaluation of Heavy Metal Species in Bottom Sediments from Imo River System, South eastern Nigeria. Res. J. Chem. Sci. 4(6): 23-30.

Smedley, PL (2002). A review of the source, behaviour and distribution of arsenic in natural waters. Applied Geochemistry. 17(5): 517-568.

Sparks, DL (1995). Environmental soil chemistry. Academic Press, San Diego.

Tamunobereton-ari, I; Omubo-Pepple, VB; Tamunobereton-ari, NA (2011). Speciation of heavy metals $(\mathrm{Cu}, \mathrm{Pb}, \mathrm{Ni})$ pollutants and the vulnerability of groundwater resource in Okrika of Rivers State, Nigeria. Am. J. Sci. Ind. Res. 2(1): 6977.

Tessier, A; Campbell, PG; Bisson, M (1979). Extraction procedure for the speciation of particulate trace metals. Anal. Chem. 51(7): 844.

Ure, AM; Quevauviller, PH; Muntau, H; Griepink, B (1993). Speciation of heavy metals in soils and sediments. An account of the improvement and harmonization of extraction techniques undertaken under auspices of the BCR of the Commission of the European Communities. Int. J. Environ. Anal. Chem. 51: 135.

Zeien, HG; Bruemmer, W (1989). Chemische Extraktionen zur Bestimmung von Schwermetallbindungsformen in Boeden. Mitteilungen der Deutschen Bodenkundlichen Gesellschaft. 59: 505-510. 